\title{
Research on Identification Method of Scour Depth for Bridge Based on ERA and SVM
}

\author{
Xiaozhong Zhang, ${ }^{1,2,3}$ Wenjuan Yao, ${ }^{3}$ Yimin Liu, ${ }^{3}$ and Bo Chen ${ }^{1}$ \\ ${ }^{1}$ School of Architectural Engineering, Quzhou University, Quzhou, Zhejiang 324000, China \\ ${ }^{2}$ Hunan Province Research Center for Safety Control Technology and Equipment of Bridge Engineering, \\ Changsha University of Science \& Technology, Changsha, Hunan 410114, China \\ ${ }^{3}$ Department of Civil Engineering, Shanghai University, Shanghai 200072, China
}

Correspondence should be addressed to Xiaozhong Zhang; 13567002601@126.com

Received 2 July 2014; Revised 2 December 2014; Accepted 16 December 2014

Academic Editor: Vadim V. Silberschmidt

Copyright (C) 2015 Xiaozhong Zhang et al. This is an open access article distributed under the Creative Commons Attribution License, which permits unrestricted use, distribution, and reproduction in any medium, provided the original work is properly cited.

\begin{abstract}
A new damage identification method for bridge scour was proposed, in the case that it was difficult to detect bridge scour depth applying testing equipment. Through integrative application of the eigensystem realization algorithm (ERA) and method of support vector machine (SVM), this method was used to identify the scour depths of bridge under conditions of ambient excitation. The following three steps are necessary for the application of this method to identify bridge scour. Firstly, a sample library about scour depth and upper structure vibration response was established using numerical methods and support vector machine method. Secondly, free response signal of bridge were extracted from random vibration signal of bridge upper structure using random decrement technique. Thirdly, based on above two steps, the bridge scour depth was identified using ERA and SVM. In the process of applying the method to identify bridge scour depth, the key is to find the sensitive points for scour depth of substructure using sample library and to gather the vibration response signal of accelerated velocity under conditions of ambient excitation. It was identified that the method has higher recognition accuracy and better robustness through experiments on a real bridge. The method provided a new way for identifying scour depth of bridges.
\end{abstract}

\section{Introduction}

Since the piers of river-crossing bridge are usually built above riverway and due to the souring floods, the river bottom elevation dramatically decreases and the real stress on pile foundations and piers differs much from initially designed stress, which greatly damps the antirisk capability of piers and pile foundations, arousing severe security hidden trouble. Therefore it increasingly grasps the attention in bridge engineering industry. According to a survey on bridge collapses in both China and foreign countries, the scouring situation on bridges is the major factor leading to current collapses [1-4]. In order to avoid bridge collapse caused by scouring floods, it requires not only to regularly evaluate bridge health condition, but also to quickly detect the scouring status and evaluate the damage status particularly after floods, so that the safe operation of current bridges can be guaranteed.
However, it is not easy to directly measure the scouring condition of bridge foundations since all foundations of rivercrossing bridges and coastal bridges are laid underwater. In terms of detecting scouring condition, the underwater testing instruments have disadvantages including higher running cost, higher cost of labor and time, higher requests on technological training, and more sensitiveness to influence of floods and external environment, which create obstacle to meet the demands for accurate testing results $[5,6]$. In addition, with floods increasing in flow quantity and flow speed and water level rising, the areas near piers (facing water surface) will be scoured into holes. The scour hole was filled by the particles sediment when the velocity of water decreases. These sediment filled by the particles was not compacted, so the pier was not well constrained and it is not easy to detect the filled parts using underwater instruments. Therefore, the real scour damage cannot always be embodied 
directly by the detected results coming from the underwater instruments.

Based on this situation, in recent 20 years, researchers from China and other countries have conducted a series of theoretical and experimental studies [7-34] regarding the identification technique for bridge scouring damage without application of underwater detecting instruments, which also achieves periodical research findings. However, current documents have proved that the bridge scouring status is related to the shapes and dimensions of piers and abutments, water depth, and water flowing speed, which at present are also the major 4 parameters in calculating bridge scouring degree. In scouring process, a coupling system was formed by water, soil and pier, which possesses great effects on bridge scouring. Therefore, a challenging subject emerges in bridge engineering: how to increase the identification accuracy of bridge scouring damage in full consideration of the coupling system.

According to above questions, in this paper, through integrating author's existing research findings, a healthy identification technique for bridge scouring damage was established with the utilization of a mature damage identification based on upper structure vibration performance and SVM method. With this technique, according to the analysis on vibration performance of bridge upper structure, a quick identification on pier scouring damage can be conducted in terms of scouring position, scouring degree, and development tendency after scouring, which provide reliable references for bridge maintenance institutions to conduct timely security evaluation on postfloods bridges.

\section{Fundamental Theory}

2.1. Eigensystem Realization Algorithm (ERA). ERA is actually a method of constructing Hankel matrix $H(k)$ through impulse response (free response) signal $h(k)$ and obtaining minimal realizations $[R, S, T]$ in the system using Singular Value Decomposition. Providing the impulse (free) response matrix already given, the Hankel matrix can be shown as follows:

$$
\begin{aligned}
& H(k) \\
& =\left[\begin{array}{cccc}
h(k+1) & h(k+2) & \ldots & h(k+\alpha) \\
h(k+2) & h(k+3) & \ddots & h(k+\alpha+1) \\
\vdots & \vdots & \ddots & \vdots \\
h(k+\beta) & h(k+\beta+1) & \cdots & h(k+\alpha+\beta+1)
\end{array}\right] .
\end{aligned}
$$

Theoretically, the impulse response signal $h(k)$ order number should be equal to the system order number, both of which are constant value. However, due to the existence of noise during signal gathering process, the $H(k)$ will decrease in terms of order number, and only when $\alpha, \beta$ values are large enough, the order number of Hankel matrix $H(k)$ can be stable. Therefore, in order to obtain a constant order number of $H(k)$, proper values of $\alpha, \beta$ are necessary and the order numbers of $\alpha, \beta$ should be kept least. Normally in one system, there are countless realizations, where different stimulations will produce different responses, while the minimal realization of different stimulations remains the same, and the minimal realization in the system is the inherent characteristic parameter of the system.

According to the definition of minimal realization, $H(k)$ can be represented by minimal realization parameters:

$$
H(k)=\left[\begin{array}{cccc}
T R^{k} S & T R^{k+1} S & \cdots & T R^{k+\beta-1} S \\
T R^{k+1} S & T R^{k+2} S & \cdots & T R^{k+\beta} S \\
\vdots & \vdots & \vdots & \vdots \\
T R^{k+\alpha-1} S & T R^{k+\alpha} S & \cdots & R S^{k+\beta+\alpha-1} T
\end{array}\right] ;
$$

suppose that

$$
\begin{aligned}
P_{\alpha} & =\left[\begin{array}{llll}
T & T R & \cdots & T R^{\alpha-1}
\end{array}\right]^{T}, \\
Q_{\beta} & =\left[\begin{array}{llll}
S & S R & \cdots & S R^{\beta-1}
\end{array}\right], \\
\text { so: } H(k) & =P_{\alpha} R^{k} Q_{\beta} ;
\end{aligned}
$$

suppose $I_{i}$ is the unit matrix with order number of $i$, and $0_{i}$ is the zero matrix with order number of $i$, now matrix $E_{m}^{T}$ and $E_{n}^{T}$ were introduced as follow:

$$
\begin{aligned}
E_{m}^{T} & =\left[\begin{array}{llll}
I_{m} & 0_{m} & \cdots & 0_{m}
\end{array}\right], \\
E_{n}^{T} & =\left[\begin{array}{llll}
I_{n} & 0_{n} & \cdots & 0_{n}
\end{array}\right] .
\end{aligned}
$$

We conclude that

$$
H(k+1)=E_{m}^{T} H(k) E_{n} ;
$$

suppose that

$$
Q_{\beta}=\Sigma_{n}^{1 / 2} V_{n}^{T},
$$

where $\Sigma$ is

$$
\begin{aligned}
\Sigma_{n} & =\operatorname{diag}\left(d_{1}, d_{2}, \ldots, d_{n}\right) \\
U^{T} U & =V^{T} V=1 .
\end{aligned}
$$

$V$ is the orthogonal matrix, so

$$
H(0)=U \Sigma V^{T} .
$$

To sum up formulas, Equation (10) can be obtained as following:

$$
\begin{aligned}
H & (k+1) \\
& =E_{m}^{T} U \Sigma^{1 / 2}\left[\Sigma^{-1 / 2} U^{T} H(1) V \Sigma^{-1 / 2}\right]^{k} \Sigma^{1 / 2} V^{T} E_{n} .
\end{aligned}
$$

Equation (10) is the basic equation for ERA; combining (4), the minimal realization of the system can be obtained:

$$
\begin{aligned}
& R=\Sigma^{-1 / 2} U H(1) V \Sigma^{-1 / 2}, \\
& S=\Sigma^{1 / 2} V^{T} E_{n}, \\
& T=E_{m}^{T} U \Sigma^{1 / 2} .
\end{aligned}
$$

At last, through eigenvalue decomposition on (11), the system modal parameter can be figured out. 


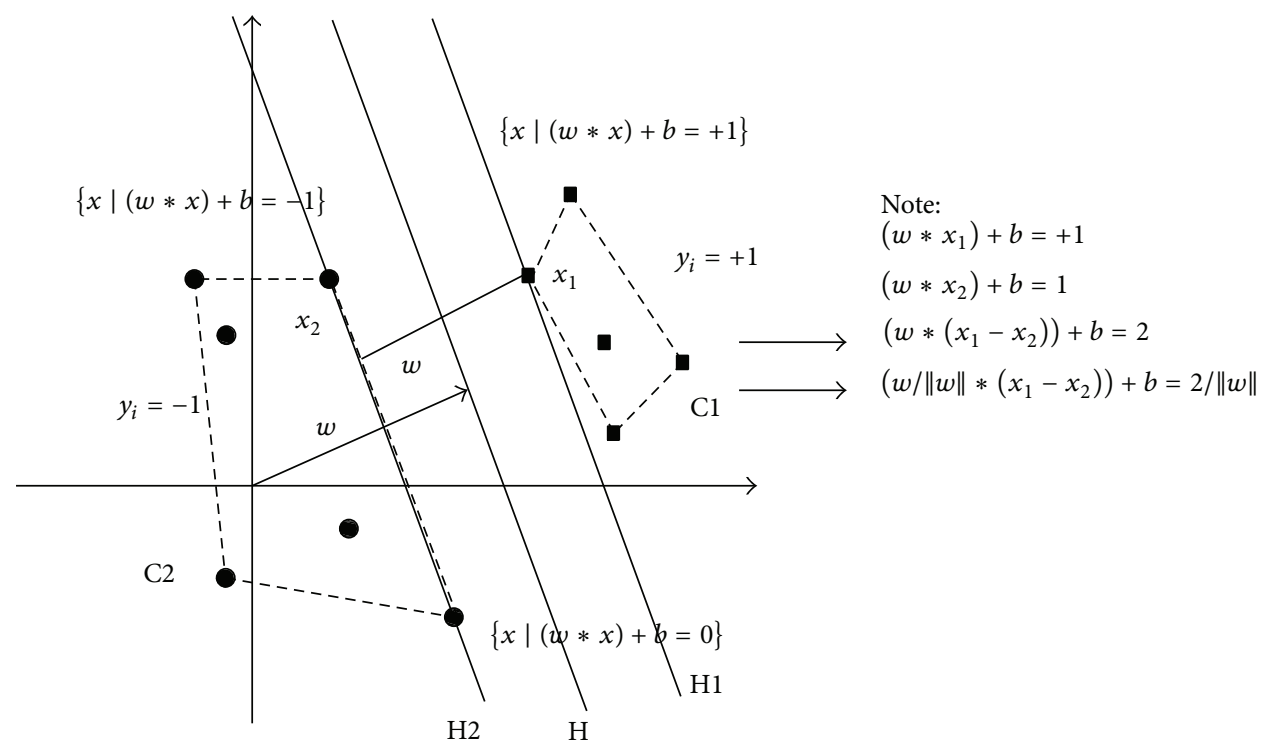

FIgURE 1: Theory of support vector machine.

2.2. Support Vector Machine [33]. Support vector machine (SVM) is a processing method for data optimization, of which the theoretical foundation is statistical learning theory. With the application of SVM, it can successfully handle pattern recognition and regression problems and promote the function of SVM to the fields of forecast and evaluation. The mechanism of SVM is to seek a hyperplane which meets the requirements of classification, keeping the training focus point away from the classification surface as much as possible, that is, seeking a hyperplane, in two sides of which there are max margin areas. According to Figure 1, there are two types of data $\mathrm{C} 1$ and $\mathrm{C} 2$ in the planar. Through two types of samples, points most near the classification surface and training samples $\mathrm{H} 1, \mathrm{H} 2$, which locate on the hyperplane of optimal classification surface, are the support vector.

As shown in Figure 2, suppose both sample data meet

$$
(w \cdot x)+b=0, \quad w \in R^{n}, b \in R
$$

hyperplane $H$ is

$$
\left(x_{1}, y_{1}\right), \ldots,\left(x_{l}, y_{l}\right), \quad x \in R^{n}, y \in\{-1,+1\} .
$$

In order to make classification surface equipped with classification interval and guarantee all samples are correctly classified, the classification surface should meet the following conditions:

$$
y_{i}((w \cdot x)+b) \geq 1, \quad i=1, \ldots, l,
$$

where the classification interval is $2 /\|w\|$. Therefore, the issue of optimal classification surface can be converted into the optimization issue on constraints. According to (14), it can conclude that

$$
\min \phi(w)=\frac{1}{2}\|w\|^{2}=\frac{1}{2}\left(w^{T}, w\right) .
$$

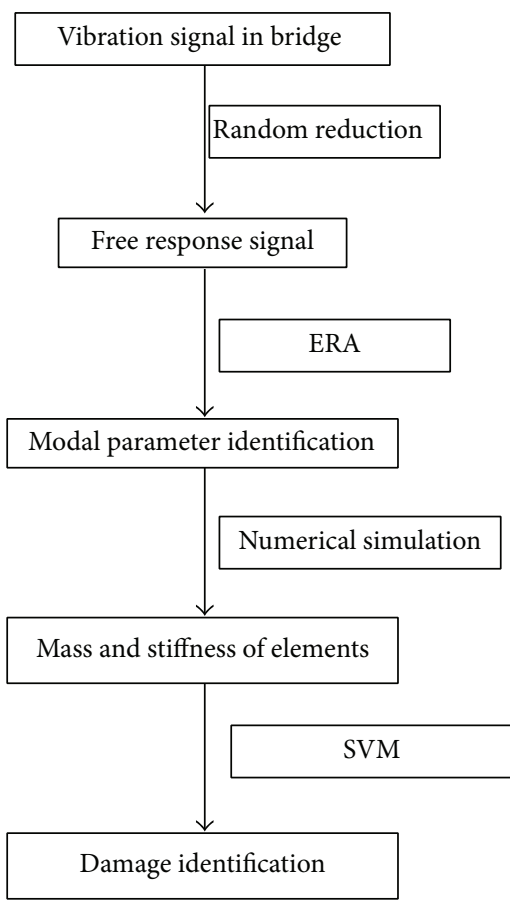

FIGURE 2: Schema of whole algorithm.

To solve (15), Lagrange function was led in

$$
L(w, a, b)=\frac{1}{2}\|w\|-a(y((w \cdot x)+b)-1) .
$$

In the equation $a$ is the Lagrange multiplier. Therefore, according to saddle point of Lagrange function, the answer of 
constrained optimization problems can be determined, and in saddle point area it should meet

$$
\begin{gathered}
\frac{\partial}{\partial w} L(w, b, a)=0, \\
\frac{\partial}{\partial w} L(w, b, a)=0 .
\end{gathered}
$$
order

To infer the optimal classification function more easily,

$$
\begin{aligned}
\sum_{i=1}^{l} a_{i} y_{i} & =0 \\
w & =\sum_{i=1}^{l} a_{i} y_{i} x_{i}, \\
a_{i} & \geq 0, \quad i=1,2, \ldots, l
\end{aligned}
$$

therefore, the quadratic optimization of the constraint can be written as

$$
W(a)=\sum_{i=1}^{l} a_{i}-\frac{1}{2} \sum_{i, j=1}^{l} a_{i} a_{j} y_{i} y_{j}\left(x_{i} \cdot x_{j}\right) .
$$

So, the Lagrange function can be changed as

$$
L(w, a, b)=\frac{1}{2}\|w\|^{2}-\sum_{i=1}^{l} a_{i} y_{i}\left(\left(w \cdot x_{i}\right)+b-1\right) .
$$

Substitute the eigenvector $\phi(x)$ for input vector $x$; then the optimal classification function can be obtained:

$$
f(x)=\operatorname{sgn}\left(\sum_{i=1}^{l} a_{i} y_{i}\left(x \cdot x_{i}\right)+b\right) .
$$

According to above equation, even in the case of higher dimensional space and during solving dual problems, the decision function and target function only have some involvement in the inner product computation between training samples, increasing the computational accuracy.

\subsection{Identification Method of Bridge Scouring Damage}

(1) Gathering Signals and Obtaining the Free Response Signals of Bridge Structure. Through observing eigenvalues algorithm, it can be seen that it is more convenient and quicker to compute the modal parameters of each order using eigenvalues algorithm after the vibration response signals are gathered. However, through analysis on the environmental excitations gathered by the sensors installed on the bridge upper structure, it turns out that the vibration response signals are neither impulse signals nor free signals. Therefore, the priority is to seek the free (impulse) response signals of the vibrational structure. The overall computational thoughts are shown in Figure 2. In order to acquire more accurate and more stable free response signals, in the paper, Random Decrement Technique with multisecant lines was adopted to eliminate the effects on signal generating, which were caused by environmental excitation.

(2) Computing Modal Parameters of Bridge Structure Using ERA Method. Through breaking down the matrix eigenvalue of bridge structure using ERA method, it can obtain the modal parameter natural frequency and modal damping ratio of the continuous system and the formation vectors of structural system, and thus the mass and stiffness of the classification unit can be obtained as well.

(3) Establishing the Relation between Scouring Depth and Modal Parameter Change Using Numerical Method. The finite element model of bridge structure was established by finite element method. And through numerical analysis, it can establish the modal parameter between scouring depth and bridge structure and the corresponding sample database.

The main factors to be considered are the following:

(a) hydrological conditions: water velocity, water depth, and so forth;

(b) geological conditions;

(c) pier geometry and shape.

(4) Computing the Scouring Depth of Bridge Structure Using SVM Method. The scouring depth was judged according the data gathered on the bridge upper structure and the relations between scouring depth and modal parameter change.

\section{Example Verification}

3.1. Project Profile. "Kezhushan" bridge (Figure 3) is a Port Mann Bridge with connection section main bridge winging 332 meters long, which is pulled up by twin towers and double cable plane cable-stayed bridge with concrete composite beams. The main bridge adopts double steel girders and steel-added beam section, and the bridge deck is made of reinforced concrete. The approach bridge adopts prestressed continuous concrete beam with the length of 50 meters. Under bridge, the water flowing speed is fast, making a severe scouring to the piers.

\subsection{Gathering the Vibration Signals of Bridge Upper Structure.} Acceleration sensors were set on upper structures according to practical requirements, and the detailed assignment is shown in Figure 4. There are 7 positions, A, B, C, D, E, F, and $G$, in each fracture surface where totally 140 acceleration sensors were installed 5 meters a line. Under the environmental excitation, the LMS data collection system (see it in Figure 5) was adopted to collect and save the data from 140 sensors. In Figure 6, it shows the acceleration data in 3 testing spots including pillar, middle beam, pillar beam on bridge floor. In this paper, by taking the fracture surface at 125 meters point as example, the superiority of identification method of scouring damage based on ERA and SVM was demonstrated. 


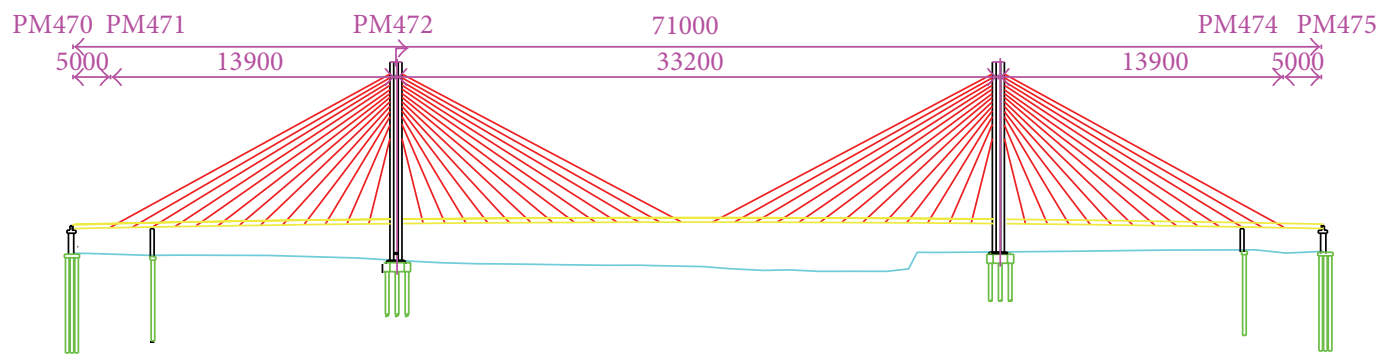

FIGURE 3: Elevational view of the Kezhushan bridge.

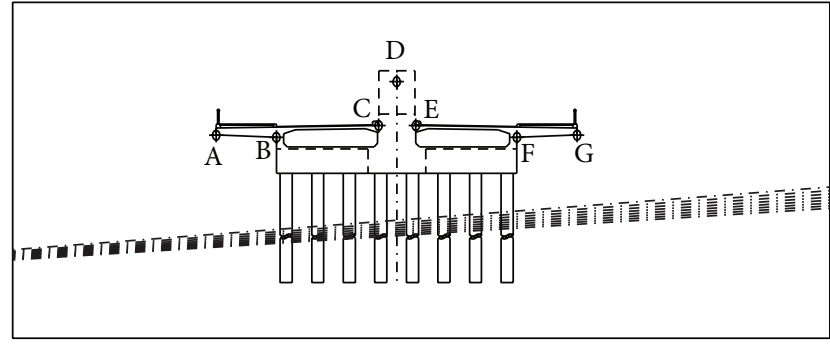

FIgURE 4: Arrangement of acceleration sensor on the bridge.

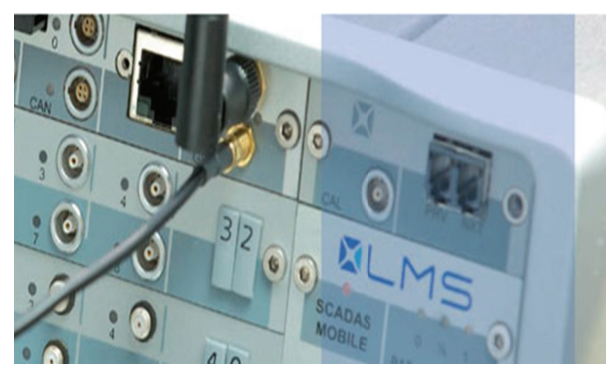

FIGURE 5: Data acquisition system of LMS.

3.3. Establishing Sample Database Using Numeric Method. Firstly set up the finite element modal of bridge structure according to design paper; see Figure 7. Since the piers were buried in different depth, according to the practical engineering geology situation, there were 21 different burial depths set in the positions in Figure 4, where each free response vibration was, respectively, conducted under transient excitation condition. At 125-meter point, the sections A$\mathrm{G}$ were tested in terms of the corresponding relation between vibration response and burial depth; see Figures 8 and 9. According to Figures 8-9, it can be seen that, at 125 -meter point of cross section, the scouring depth is sensitively related to the $Z$-direction accelerations of $\mathrm{A}, \mathrm{E}, \mathrm{F}$, and $\mathrm{G}$ points, while the scouring depth is sensitively related to the $Y$-direction accelerations of $F, G$ points.

3.4. Bridge Scouring Damage Identification. With the usage of gathered data, the modal parameter of bridge substructure can be obtained using ERA and the stiffness of buried units of the substructure can be detected as well. Taking the No. 78 cross section at $125 \mathrm{~m}$ point as example, the No. 78 pier can be

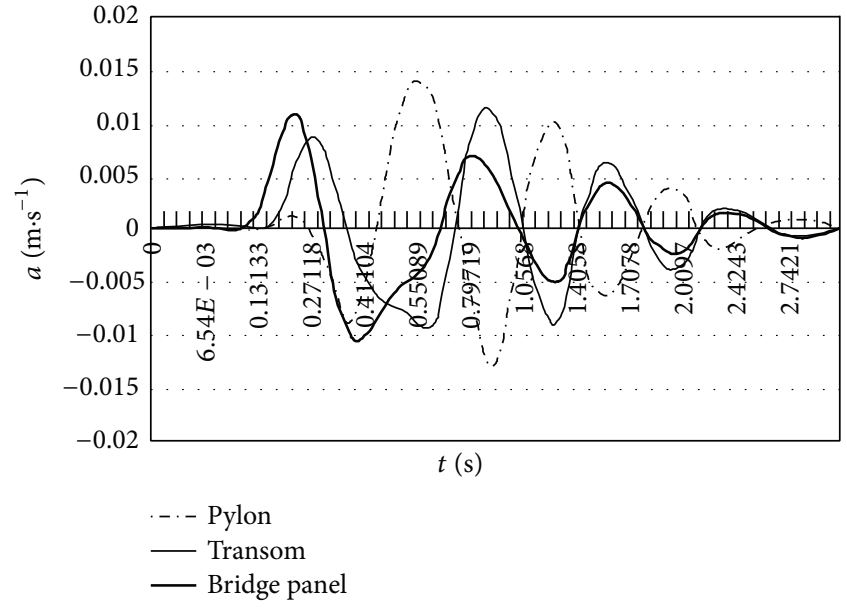

Figure 6: Acceleration data at 125 meters point.

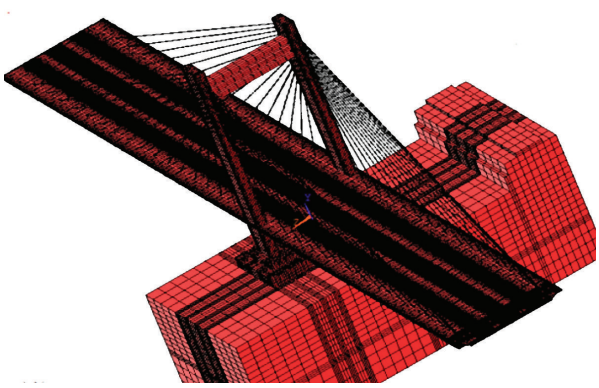

Figure 7: Finite element model.

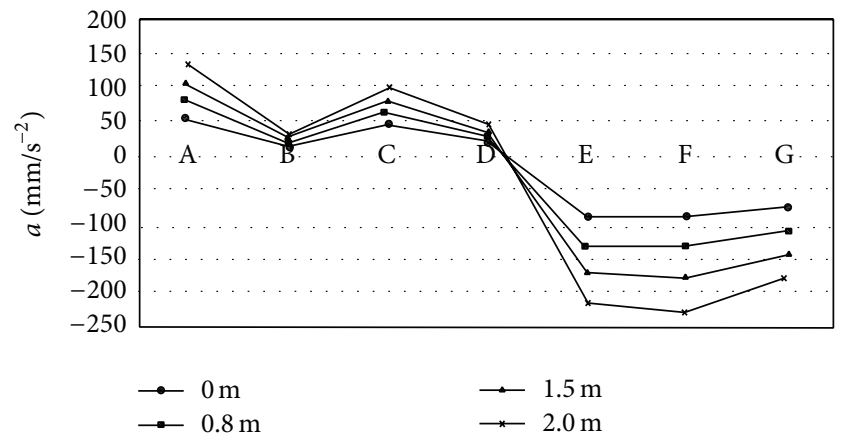

FIgURE 8: Z-direction acceleration diagram. 


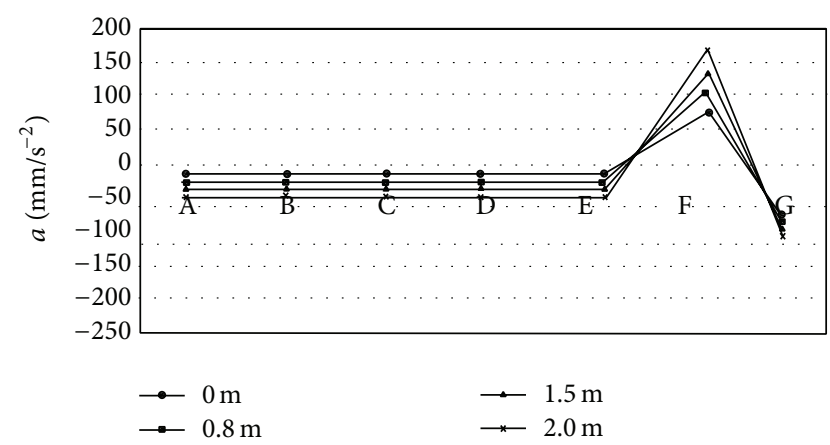

Figure 9: $Y$-direction acceleration diagram.

divided into 41 units, which was shown in Figure 10. Among these 41 units, the stiffness in different burial depths is shown in Table 1. It indicates that with the burial depth varying, the horizontal stiffness of pier was obviously changed after scouring, while the horizontal stiffness of unscoured sector remained unchanged, and thus the scouring depth of piers can be judged.

3.5. Bridge Scouring Depth Identification. Identify the bridge scouring depth with overall application of ERA method and SVM method. After processing the G point and F point, the horizontal stiffness of each unit of pier 78 at 125-meter cross section was successfully identified, and the results can be seen in Figure 11. At points F and G, the scouring situation of units 1256-1265 can be identified obviously, and thus the scouring depth $(10 * 0.1 \mathrm{~m})$ of pier 78 can be identified according to the unit dimension.

\section{Conclusions}

In this paper, an identification method on scouring damage of bridge structure based on ERA and SVM was established through theoretical derivation. And this method was verified in terms of identification accuracy and robustness under environmental excitation condition through real bridge test. Conclusions are as follows:

(1) The identification method on scouring damage of bridge structure based on ERA and SVM can well identify the scouring depth of bridge substructure (underwater section) owing to its excellent testability on upper structure.

(2) According to the real bridge test, the method proposed in this paper has higher identification accuracy and convenient practicality.

(3) The analysis on identification method of scouring damage of bridge structure based on ERA and SVM provided a new approach for monitoring the scouring depth of cross-river bridges and cross-sea bridges.

The real bridge test was conducted under good environment condition, while in practical operation, current bridges are surrounded with complex environment conditions with bigger noise. Therefore, how to eliminate the noise effect
TABLE 1: Horizontal stiffness of each unit for pier 78 at different depths $(\mathrm{KN} / \mathrm{m})$.

\begin{tabular}{|c|c|c|c|c|}
\hline \multirow{2}{*}{ Unit } & \multicolumn{4}{|c|}{ Burial depth/m } \\
\hline & 0 & 0.8 & 1.5 & 2.0 \\
\hline 1256 & 17.90 & 16.87 & 15.98 & 13.56 \\
\hline 1257 & 17.90 & 16.87 & 15.98 & 13.67 \\
\hline 1258 & 17.93 & 16.75 & 16.13 & 13.69 \\
\hline 1259 & 17.95 & 16.75 & 16.12 & 13.74 \\
\hline 1260 & 17.95 & 16.69 & 16.12 & 13.74 \\
\hline 1261 & 17.96 & 16.68 & 16.12 & 13.96 \\
\hline 1262 & 17.96 & 16.62 & 16.24 & 13.97 \\
\hline 1263 & 17.96 & 16.61 & 16.24 & 14.05 \\
\hline 1264 & 17.96 & 16.60 & 16.60 & 14.08 \\
\hline 1265 & 17.96 & 16.60 & 16.60 & 14.11 \\
\hline 1266 & 17.96 & 17.96 & 16.79 & 14.20 \\
\hline 1267 & 17.96 & 17.96 & 16.86 & 15.86 \\
\hline 1268 & 17.96 & 17.96 & 16.93 & 15.93 \\
\hline 1269 & 17.96 & 17.96 & 16.96 & 15.96 \\
\hline 1270 & 17.96 & 17.96 & 16.97 & 15.97 \\
\hline 1271 & 17.96 & 17.96 & 17.59 & 16.59 \\
\hline 1272 & 17.96 & 17.96 & 17.77 & 16.77 \\
\hline 1273 & 17.96 & 17.96 & 17.84 & 17.04 \\
\hline 1274 & 17.96 & 17.96 & 17.93 & 17.13 \\
\hline 1275 & 17.96 & 17.96 & 17.96 & 17.16 \\
\hline 1276 & 17.96 & 17.96 & 17.96 & 17.38 \\
\hline 1277 & 17.96 & 17.96 & 17.96 & 17.45 \\
\hline 1278 & 17.96 & 17.96 & 17.96 & 17.67 \\
\hline 1279 & 17.96 & 17.96 & 17.96 & 17.77 \\
\hline 1280 & 17.96 & 17.96 & 17.96 & 17.84 \\
\hline 1281 & 17.96 & 17.96 & 17.96 & 17.90 \\
\hline 1282 & 17.96 & 17.96 & 17.96 & 17.94 \\
\hline 1283 & 17.96 & 17.96 & 17.96 & 17.96 \\
\hline 1284 & 17.96 & 17.96 & 17.96 & 17.96 \\
\hline 1285 & 17.96 & 17.96 & 17.96 & 17.96 \\
\hline 1286 & 17.96 & 17.96 & 17.96 & 17.96 \\
\hline 1287 & 17.96 & 17.96 & 17.96 & 17.96 \\
\hline 1288 & 17.96 & 17.96 & 17.96 & 17.96 \\
\hline 1289 & 17.96 & 17.96 & 17.96 & 17.96 \\
\hline 1290 & 17.96 & 17.96 & 17.96 & 17.96 \\
\hline 1291 & 17.96 & 17.96 & 17.96 & 17.96 \\
\hline 1292 & 17.96 & 17.96 & 17.96 & 17.96 \\
\hline 1293 & 17.96 & 17.96 & 17.96 & 17.96 \\
\hline 1294 & 17.96 & 17.96 & 17.96 & 17.96 \\
\hline 1295 & 17.96 & 17.96 & 17.96 & 17.96 \\
\hline 1296 & 17.96 & 17.96 & 17.96 & 17.96 \\
\hline
\end{tabular}

during data testing has become the next research direction. In addition, before this method is promoted into practical production, the issue of effectively transmitting data under field environment is still needed to be addressed, which will be a tough topic needed to be overcome in the future.

\section{Conflict of Interests}

The authors declare that there is no conflict of interests regarding the publication of this paper. 


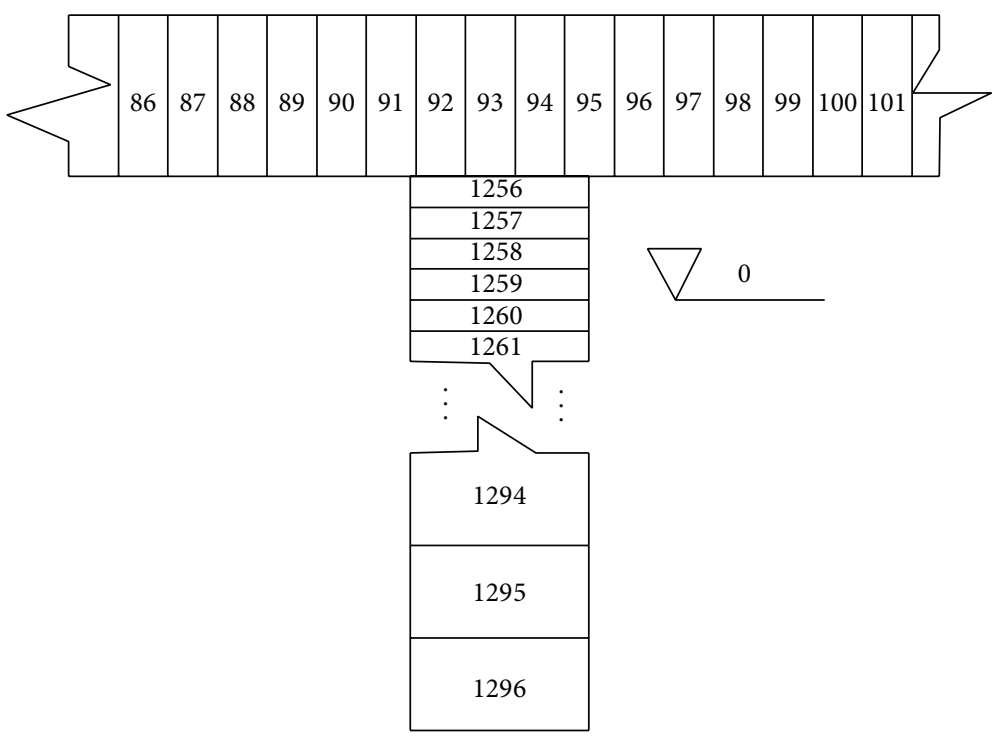

FIgURE 10: Division of units for pier 78.

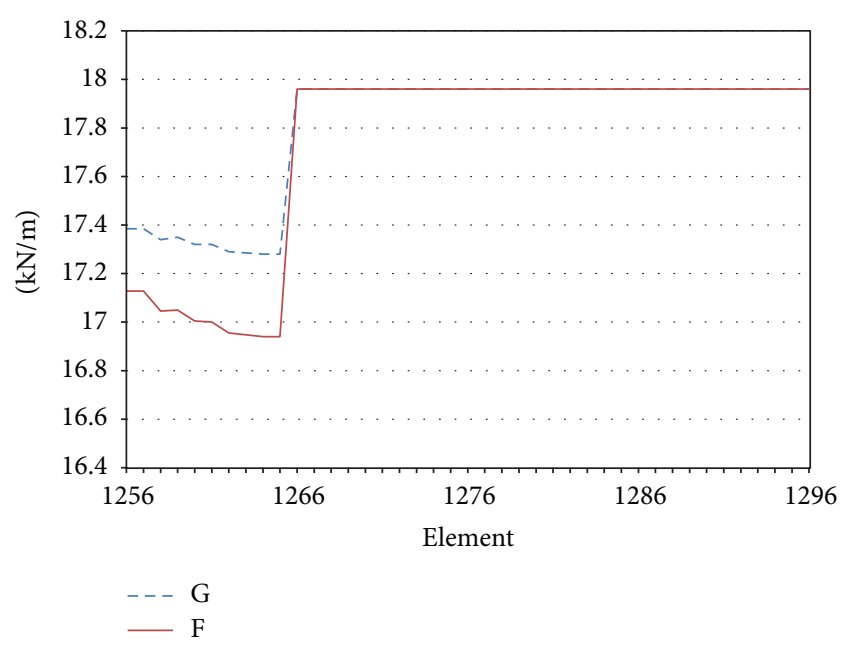

FIgURE 11: Stiffness of unit identification for pier 78.

\section{Acknowledgments}

This work was financially supported by Open Fund Project of Hunan Province Research Center for Safety Control Technology and Equipment of Bridge Engineering (Changsha University of Science \& Technology), Project no.: 13KC05. The work was financially supported by National Natural Science Foundation for the Youth (41402271) at the same time.

\section{References}

[1] B. Ji and Z. Fu, "Analysis of Chinese bridge collapse accident causes in recent years," Journal of Civil Engineering, vol. 43, supplement 1, pp. 495-498, 2010.
[2] K. Wardhana and F. C. Hadipriono, "Analysis of recent bridge failures in the United States," Journal of Performance of Constructed Facilities, vol. 17, no. 3, pp. 144-150, 2003.

[3] I. N. Robertson, R. H. Riggs, S. C. S. Yim, and Y. L. Young, "Lessons from hurricane Katrina storm surge on bridges and buildings," Journal of Waterway, Port, Coastal and Ocean Engineering, vol. 133, no. 6, pp. 463-483, 2007.

[4] M. N. Landers and D. S. Mueller, "Evaluation of selected pier-scour equations using field data," Transportation Research Record, no. 1523, pp. 186-195, 1996.

[5] E. M. Laursen and A. Toch, Scour Around Bridge Piers and Abutments, vol. 4, Iowa Highway Research Board, Ames, Iowa, USA, 1956.

[6] H. W. Shen, V. R. Schneider, and S. S. Karaki, "Local scour around bridge piers," Proceeding of ASCE, vol. 95, no. 6, pp. 19191940, 1969.

[7] B. W. Melville and A. J. Raudkivi, "Flow characteristics in local scour at bridge piers," Journal of Hydraulic Research, vol. 15, no. 4, pp. 373-380, 1977.

[8] S. R. Gorin and F. P. Haeni, "Use of surface geophysical methods to assess riverbed scour at bridge piers," Tech. Rep. 33:88-4212, Federal Highway Administration, 1989.

[9] F. de Falco and R. Mele, "The monitoring of bridges for scour by sonar and sedimetri," NDT \& E International, vol. 35, no. 2, pp. 117-123, 2002.

[10] W. A. Horne, "Scour inspection using ground penetrating radar," in Proceedings of the National Conference on Hydraulic Engineering, pp. 1888-1893, San Francisco, Calif, USA, July 1993.

[11] S. G. Millard, J. H. Bungey, C. Thomas, M. N. Soutsos, M. R. Shaw, and A. Patterson, "Assessing bridge pier scour by radar," NDT \& E International, vol. 31, no. 4, pp. 251-258, 1998.

[12] I. Park, J. Lee, and W. Cho, "Assessment of bridge scour and riverbed variation by a ground penetrating radar," in Proceedings of the 10th International Conference Ground Penetrating Radar (GPR '04), pp. 411-414, Delft, The Netherlands, June 2004.

[13] R. R. Mason and D. M. Shepard, "Field performance of an acoustic scour-depth monitoring system," in Proceedings of 
Fundamentals and Advancements in Hydraulic Measurements and Experimentation, pp. 366-375, New York, NY, USA, 1994.

[14] D. C. Hayes and F. E. Drummond, "Use of fathometers and electrical conductivity probes to monitor riverbed scour at bridges and piers," Water Resource Investigations Rep. No. 944164, U.S. Geological Survey, Hartford, Conn, USA, 1995.

[15] J. L. Humar, Dynamics of Structure, Taylor \& Francis, London, UK, 2005.

[16] L. Deng and C. S. Cai, "Bridge scour: prediction, modeling, monitoring, and countermeasures-review," Practice Periodical on Structural Design and Construction, vol. 15, no. 2, pp. 125134, 2010.

[17] X. Yu, "Time domain reflectometry automatic bridge scour measurement system: principles and potentials," Structural Health Monitoring, vol. 8, no. 6, pp. 463-476, 2009.

[18] Y.-B. Lin, J.-C. Chen, K.-C. Chang, J.-C. Chern, and J.-S. Lai, "Real-time monitoring of local scour by using fiber Bragg grating sensors," Smart Materials and Structures, vol. 14, no. 4, pp. 664-670, 2005.

[19] J.-Y. Lu, J.-H. Hong, C.-C. Su, C.-Y. Wang, and J.-S. Lai, "Field measurements and simulation of bridge scour depth variations during floods," Journal of Hydraulic Engineering, vol. 134, no. 6, pp. 810-821, 2008.

[20] G. Hearn and R. B. Testa, "Modal analysis for damage detection in structures," Journal of Structural Engineering, vol. 117, no. 10, pp. 3042-3063, 1991.

[21] J. Maeck and G. de Roeck, "Dynamic bending and torsion stiffness derivation from modal curvatures and torsion rates," Journal of Sound and Vibration, vol. 225, no. 1, pp. 153-170, 1999.

[22] A. K. Pandey and M. Biswas, "Damage detection in structures using changes in flexibility," Journal of Sound and Vibration, vol. 169, no. 1, pp. 3-17, 1994.

[23] J. M. Ricles and J. B. Kosmatka, "Damage detection in elastic structures using vibratory residual forces and weighted sensitivity," AIAA Journal, vol. 30, no. 9, pp. 2310-2316, 1992.

[24] W. Fan and P. Qiao, "A strain energy-based damage severity correction factor method for damage identification in platetype structures," Mechanical Systems and Signal Processing, vol. 28, pp. 660-678, 2012.

[25] W.-X. Ren, Z.-S. Sun, and Y. Xia, "Damage ideniifieation of shear conneetors with wavelet packet energy: laboratory test study," Journal of Structural Engineering, vol. 134, no. 5, pp. 832841, 2008.

[26] J. Lu, D. Liang, X. Zhang, and J. Zeng, "Research on structural health monitoring for wing box based on support vector regression machine," Chinese Journal of Scientific Instrument, vol. 30, no. 3, pp. 486-491, 2009.

[27] N. Stubbs and J. T. Kim, "Field verification of a nondestructive damage localization and sensitivity estimator algorithm," in Proceedings of the 13th International Modal Analysis Conference, pp. 210-218, 1995.

[28] N. Stubbs and J.-T. Kim, "Improved damage identification method based on modal information," Journal of Sound and Vibration, vol. 252, no. 2, pp. 223-238, 2002.

[29] F. N. Catbas, M. Gul, and J. L. Burkett, "Conceptual damagesensitive features for structural health monitoring: laboratory and field demonstrations," Mechanical Systems and Signal Processing, vol. 22, no. 7, pp. 1650-1669, 2008.

[30] J. Zhao and J. T. DeWolf, "Sensitivity study for vibrational parameters used in damage detection," Journal of Structural Engineering, vol. 125, no. 4, pp. 410-416, 1999.
[31] X. Zhang and W. Yao, "Structural damage identification using element strain energy method based on sensitive modals," Journal of Central South University (Science and Technology), vol. 44, no. 7, pp. 3014-3023, 2013.

[32] S. Foti and D. Sabia, "Influence of foundation scour on the dynamic response of an existing bridge," Journal of Bridge Engineering, vol. 16, no. 2, pp. 295-304, 2011.

[33] X. Zhang, W. Yao, and F. Tian, "Structural damage identification based on time-varying ARMA model and support vector machine," Journal of Basic Science and Engineering, vol. 21, no. 6, pp. 1094-1102, 2013.

[34] X.-Z. Zhang and W.-J. Yao, "Small damage high-precision identification of serving structural pile," Journal of Beijing University of Technology, vol. 39, no. 10, pp. 1499-1504, 2013. 

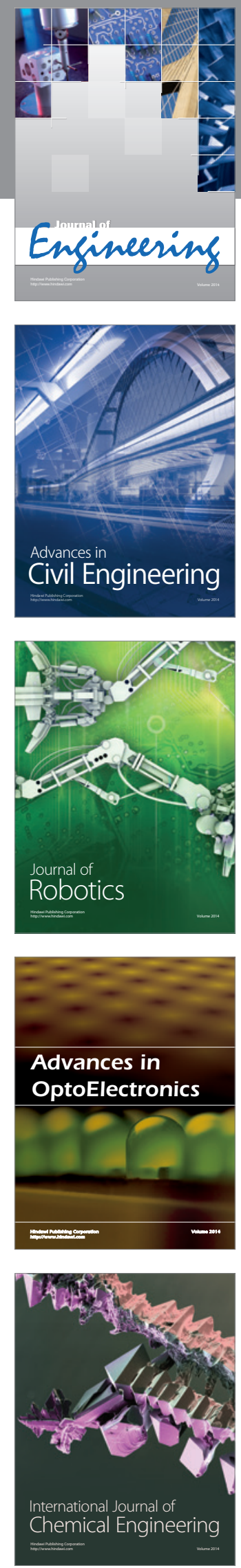

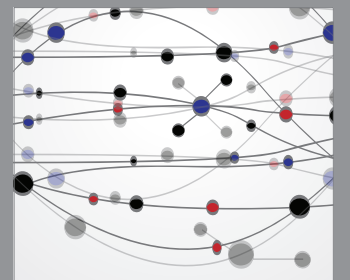

The Scientific World Journal
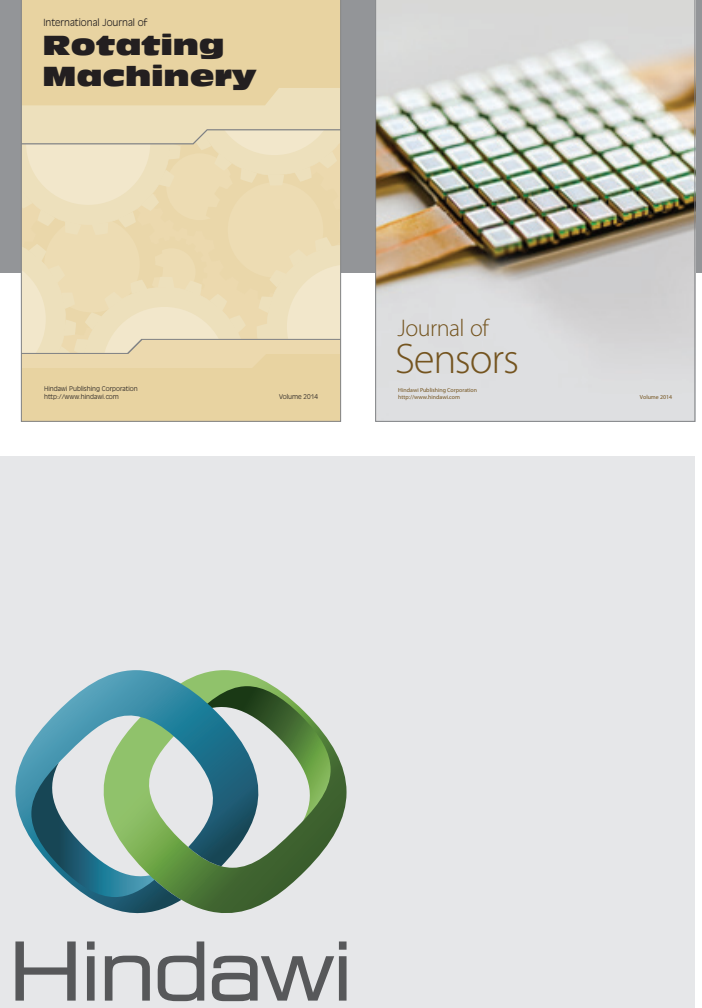

Submit your manuscripts at http://www.hindawi.com
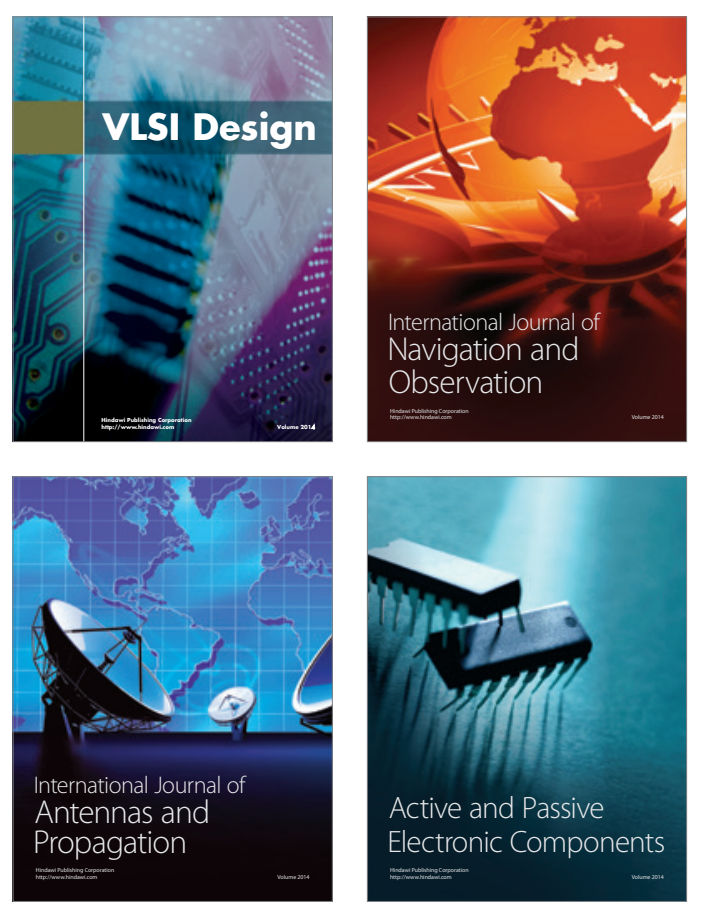
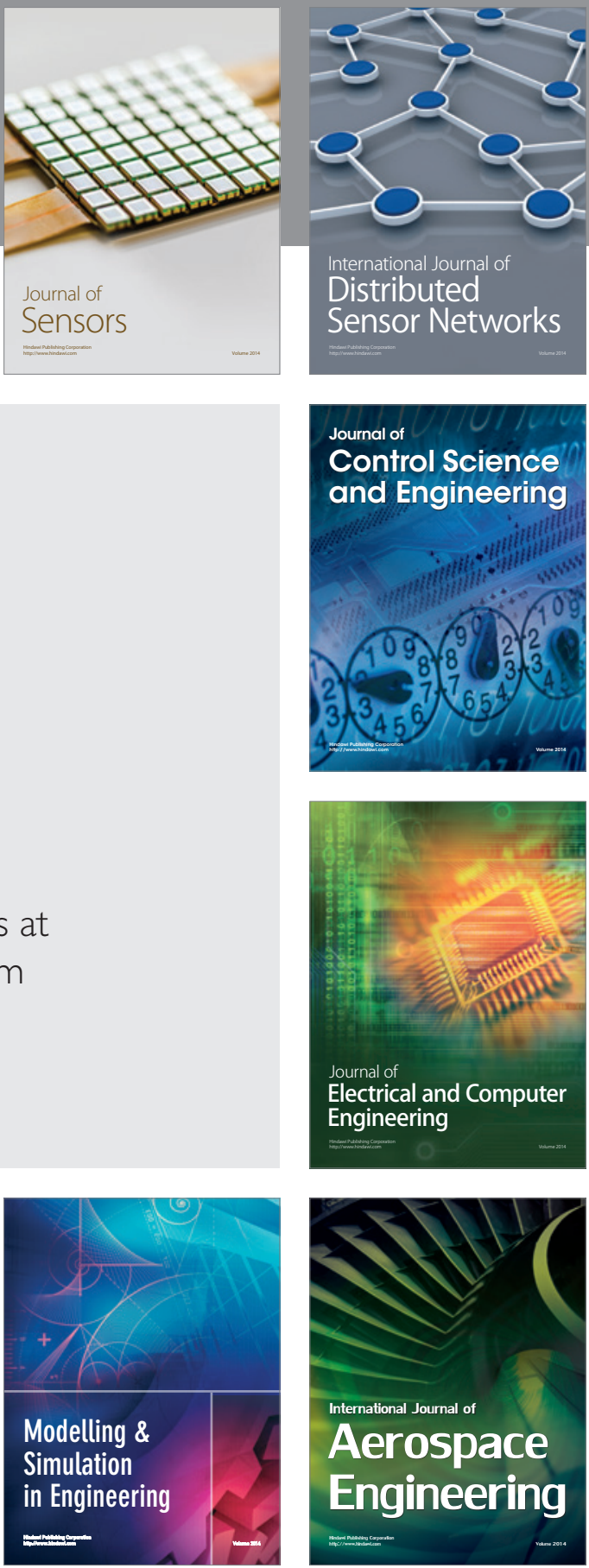

Journal of

Control Science

and Engineering
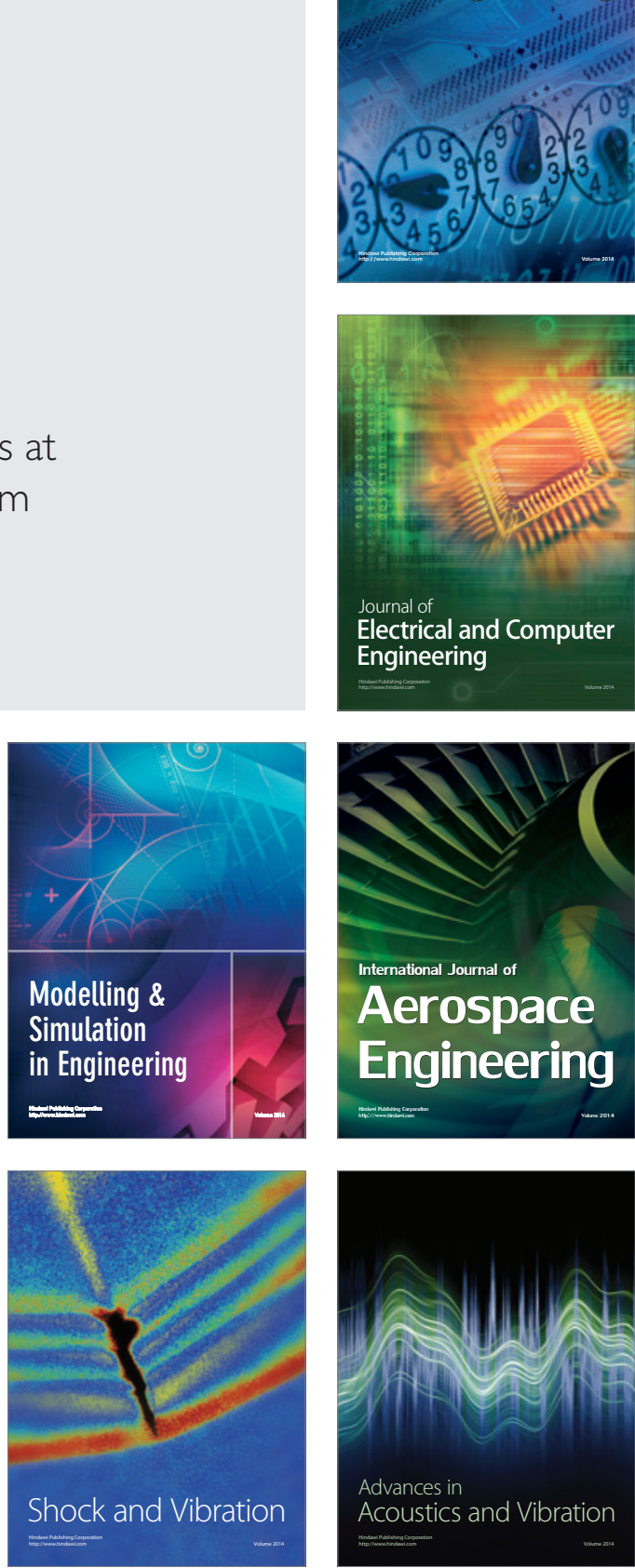